\title{
FOLHAS VERDES, FOLHAS SECAS, FIBRA DO COLMO E A CLARIFICAÇÃO DO CALDO DE CANA-DE-AÇÚCAR
}

\author{
Roberto Bovi ${ }^{1}$; Gil Eduardo Serra²* \\ ${ }^{1}$ Depto. de Agroindústria, Alimentos e Nutrição - USP/ESALQ, C.P. 9 - CEP: 13418-900 - Piracicaba, SP. \\ 2Depto. de Tecnologia de Alimentos-FEA/UNICAMP, C.P. 6121 - CEP: 13081-970 - Campinas, SP. \\ ${ }^{*}$ Autor correspondente <gilserra@fea.unicamp.br>
}

RESUMO: A presença de impurezas vegetais, como folhas verdes e secas, nos carregamentos de cana-deaçúcar entregues nas usinas de açúcar, tem preocupado os técnicos não somente por se tratar de um material sem qualquer valor tecnológico para processamento, como ainda por poder causar aumento na cor do caldo clarificado e conseqüentemente na cor do açúcar produzido, com redução de sua qualidade para o mercado; outro problema é o volume do lodo decantado nos clarificadores, cujo aumento causa maior recirculação e maior volume do caldo filtrado, com maiores perdas de sacarose e maior utilização dos filtros rotativos a vácuo. O trabalho teve como objetivo avaliar a clarificação do caldo de cana-de-açúcar com a adição de folhas verdes e folhas secas, tendo como controle a adição de fibra do colmo. Os ensaios foram delineados tendo como base a adição de quantidades das fontes fibrosas - folha verde, folha seca e fibra do colmo para formular amostras que correspondessem a acréscimos absolutos de $0,25,0,50$ e 0,75 ponto percentual sobre o teor de fibra do colmo da cana. Os efeitos sobre a clarificação do caldo, conduzida em clarificador de bancada em laboratório, foram avaliados pela cor do caldo clarificado e o volume de lodo decantado. $\mathrm{Na}$ presença de folhas verdes ocorreu uma elevação da cor do caldo clarificado e do volume de lodo decantado. Da folha verde são extraídos água e compostos que são responsáveis por alterações na composição do caldo; devido à presença de componentes não-sacarose o extrato foliar interfere na clarificação do caldo. Da folha seca também foram extraídos compostos solúveis, todavia não detectados através das análises do caldo. A fibra do colmo não afetou a clarificação.

Palavras chave: cana-de-açúcar, impureza, folha, clarificação

\section{GREEN LEAVES, DRY LEAVES, STALK FIBER AND THE CLARIFICATION OF SUGARCANE JUICE}

\begin{abstract}
The presence of vegetal impurities in sugarcane delivered to sugarmills as green and dry leaves is a problem not only because they are non-value materials to be processed along with sugarcane stalks, but also because they can rise the color of the clarified juice and, consequently, the color of the sugar produced, with a reduction of its quality for the market. Another problem is the mud volume sedimented in the clarifiers, which also can result in a larger recirculation and greater volume of filtrate juice, with higher losses of sucrose and utilization of the vacuum rotary filters. The objective of this work was to observe the effect of the presence of green and dry leaves on sugarcane juice clarification, related to a control treatment with the addition of fiber extracted from the stalks. The experiments were planned based on the addition of quantities of fibrous sources in order to formulate samples with absolute increase of $0.25,0.50$ and 0.75 percentual points over the fiber content of the sugarcane stalks (control treatment). The juice clarification was conducted with a laboratory clarifier. The clarified juice color and the mud volume were evaluated. The presence of green leaves caused higher color and mud volume due to the extraction of non-sucrose components of the leaves. Soluble compounds of dry leaves were also extracted, though not detected by juice analysis. The addition of the fiber extracted from the stalks did not induce alterations in the clarification process.
\end{abstract}

Key words: sugarcane, impurity, trash, leaf, clarification

\section{INTRODUÇÃO}

A quantidade e o tipo de impurezas presentes na matéria-prima têm influência sobre diversos parâmetros da composição do caldo da cana-de-açúcar, tais como Brix, Pol, açúcares redutores e cinzas.

As principais impurezas vegetais provêm da própria planta de cana-de-açúcar e podem ser constituídas por folhas verdes e folhas secas, cartuchos, palmitos e chupões. Também participam o solo e, em alguns casos, ervas daninhas que infestam o canavial sem o devido controle. A prática da queima do canavial altera a composição e proporção de impurezas em relação à cana crua. As impurezas causam um aumento da fibra industrial e, consequentemente, redução na capacidade de moagem e extração.

Este estudo envolveu o efeito de fontes distintas de fibras como folha verde e folha seca e também o efeito da própria fibra do colmo da cana que foi incluída para servir como referencial para avaliação do efeito de adição das outras fontes. Outra particularidade deste estudo é a adição das diversas impurezas de modo que 
os tratamentos tenham como base comum a adição de teores de fibras idênticos.

Arceneaux \& Davidson (1973) realizaram experimentos com folhas secas e verdes com o cuidado de adicionar tais impurezas em quantidades equivalentes em matéria seca. Os experimentos foram conduzidos com extração de caldo em moenda de laboratório. Concluem que a folha verde contribui com maior quantidade de impurezas no caldo, do que a quantidade equivalente de folha seca. Esses autores ressaltam que as folhas secas que utilizaram foram aquelas que secaram e permaneceram presas ao colmo em crescimento. Nessas condições, a maior parte dos sólidos solúveis dessas folhas secas já foi translocado para o colmo durante o processo de envelhecimento. A matéria seca da folha verde possui, em média, o dobro dos sólidos solúveis da folha seca. Os resultados de análises do caldo mostram que a presença da folha verde diminuiu a Pol do caldo e sua pureza, de forma mais marcante e em maior proporção do que a folha seca. Quanto às cinzas e nitrogênio no caldo, a folha verde causou sua elevação em maior proporção que a folha seca, sendo que o nitrogênio permaneceu praticamente inalterado com a adição de folha seca.

Balch \& Broeg (1948) são da opinião que as impurezas da cana não têm nenhum efeito operacional pronunciado sobre o processo de clarificação, mas diminuem a qualidade do caldo clarificado aumentando a cor e a turbidez e o teor de não-açúcares. Ivin \& Doyle (1989) trabalhando com impurezas constituídas de folhas verdes, equivalentes a $6 \%$, observaram redução na Pol em 0,71 unidades e aumento dos açúcares redutores do caldo em 0,05 unidades. A pureza do caldo foi reduzida em 1,2 unidades, a cor do caldo misto aumentou $25,5 \%$ e os caldos clarificados mostraram a cor elevada em $26,5 \%$ em relação ao controle. Na moagem industrial de cana não despontada, Zarpelon (1988) não notou diferença quanto à qualidade do caldo e do açúcar fabricado. Salienta ser conhecido o fato que pontas e folhas incorporam ao caldo maior quantidade de cor e cinzas.

Bovi \& Serra (1999) estudando o efeito de folha verde, folha seca e fibra do colmo, mostram que a presença de folhas verdes reduz o Brix, Pol e Pureza do caldo, e eleva os açúcares redutores e cinzas. Esse estudo foi conduzido de modo que as impurezas fossem comparáveis, sendo adicionada em quantidades equivalentes de modo a proporcionar aumentos iguais no teor de fibra do colmo de cana.

O objetivo deste trabalho foi avaliar o efeito da presença de folhas verdes, folhas secas e fibra do colmo na clarificação por decantação do caldo, sendo avaliados os parâmetros cor do caldo clarificado e o volume do lodo decantado.

\section{MATERIAL E MÉTODOS}

O material utilizado para a execução dos ensaios constou de colmos e lâminas de folhas verdes e folhas secas, da variedade de cana-de-açúcar SP71-6163, cujo caldo foi objeto de avaliação (Bovi \& Serra, 1999) sob os mesmos tratamentos de adição de folhas e fibra do colmo adotados neste trabalho, podendo-se ainda observar que as coletas das amostras se situaram no período de maturação (maio a setembro, 1996), no campo experimental do Departamento de Agroindústria, Alimentos e Nutrição da ESALQ, USP.

Foram conduzidos oito ensaios, correspondendo a oito amostragens realizadas de maio a setembro (1996). Cada ensaio constou de quatro tratamentos (Testemunha, Folha Verde - FV, Folha Seca - FS e Fibra do Colmo - FC), com três repetições cada. A amostragem foi realizada coletando 10 colmos consecutivos na linha de plantio. Após o corte basal do colmo, foram coletadas as frações de lâminas de folhas verdes e folhas secas, descartando aquelas situadas na região de transição, assim como o palmito e o ponteiro que foram separados com corte no ponto natural de quebra. As bainhas foram separadas e descartadas.

As amostras foram coletadas no campo, sempre no dia anterior à realização de cada ensaio de laboratório, e amostras de colmo, folha verde e folha seca foram analisadas quanto ao teor de fibra. De uma amostra de colmos foi extraída a fibra que foi seca em estufa. Assim, foram obtidas as 3 frações para compor os tratamentos dos ensaios (FV, FS e FC).

A formulação dos tratamentos em cada ensaio baseou-se nos teores de fibra dos materiais, analisados em dias anteriores e conservados sob refrigeração. Os dados médios do teor de fibra na folha verde, folha seca e fibra do colmo foram, respectivamente, de 16,03\%, $62,31 \%$ e $99,3 \%$.

\section{Preparo do Material}

O colmo da cana foi desintegrado em desfibrador e a seguir homogeneizado em uma betoneira para compor os tratamentos e extração da fração de fibra do colmo.

Para a extração de fibra, a cana desintegrada foi colocada em sacos de tecido de algodão, lavada em água corrente e espremida até que a água de lavagem não apresentasse turbidez visível; a seguir os sacos foram colocados em vasilhames com água fervente, desligando-se a seguir o aquecimento e deixando por 1 hora com agitação a cada 10 minutos. Os sacos foram lavados novamente em água corrente, até que a água de lavagem não apresentasse turbidez visível. Em seguida foram colocados em estufa de secagem, a $100^{\circ} \mathrm{C}$, até peso constante. Esta metodologia foi adaptada do método de determinação de fibra, segundo Clayton (1971). 
A fração de folha verde foi desintegrada em moinho de martelos de laboratório, e a seguir peneirada em malha $0,5 \mathrm{~mm}$ para homogeneização da fração. As frações de folha seca e fibra do colmo tiveram tratamento idêntico.

O extrato obtido através de extração a frio, em digestor com agitação mecânica, revelou que apenas da folha verde foram extraídos componentes solúveis. A análise centesimal do extrato obtido com $100 \mathrm{~g}$ de material e $1.000 \mathrm{~mL}$ de água destilada foi realizada também para a bainha da folha, apenas para caracterizar esse material (TABELA 1).

\section{Tratamentos}

Os tratamentos foram elaborados, tendo como base quantidades padronizadas de fibra, com a adição de folha verde, folha seca ou fibra do colmo, à cana desintegrada. Os níveis de fibra adicionados através de cada uma das fontes, foram calculados para elevar o teor de fibra da cana desintegrada em $0,25,0,50$ e $0,75 \%$ ponto percentual.

Em cada ensaio, com base na análise do teor de fibra de cada fonte, foi realizado o cálculo da quantidade equivalente a ser adicionada em folhas verdes, folha seca ou fibra da cana. Em média, para a composição dos tratamentos, foram adicionadas as quantidades apresentadas na TABELA 2.

A presença de $1 \%$ de folha verde, folha seca $e$ fibra do colmo correspondem, respectivamente, a acréscimos \% fibra na cana de 0,060, 0,521 e 0,893\%, de acordo com os dados da TABELA 2. A adição das fontes de fibra foi realizada na amostra de cana desintegrada e homogeneizada.

O cálculo da quantidade de cada fonte de fibra (folha verde, folha seca e fibra do colmo) a ser adicionada à cana foi realizado através da equação 1 , tomando como exemplo a folha verde:

$$
(100-\text { QFV)F\%C + QFV }(F \% F V)=100(F \% C+A)
$$

onde: 100 = quantidade de material (cana + folha verde), em gramas; QFV = quantidade folha verde $(\mathrm{g} \mathrm{FV} / 100 \mathrm{~g}$ material); $\mathrm{F} \% \mathrm{C}=$ fibra $\%$ cana; $\mathrm{F} \% \mathrm{FV}=$ fibra $\%$ folha verde e $\mathrm{A}=$ acréscimo $\%$ fibra na cana

Para as demais frações (folha seca e fibra do colmo), os valores de FV na equação deverão ser substituídos por FS e FC para os respectivos cálculos do peso de folha seca e de fibra do colmo, que serão adicionadas para o preparo das amostras.

\section{Ensaios}

A extração do caldo das amostras preparadas dos tratamentos foi realizada, utilizando-se uma prensa hidráulica automática, PINNET-EMIDECAU, modelo CODISTIL, exercendo-se pressão de $250 \mathrm{kgf}^{-2}$, durante o tempo de 1 minuto, conforme metodologia descrita por Tanimoto (1964).

A clarificação do caldo foi realizada pelo processo de defecação simples, utilizando-se um decantador de laboratório, constituído por provetas graduadas de $250 \mathrm{~mL}$, imersas em um banho de água, mantido em ebulição com aquecimento e homogeneização. A clarificação constou da adição de leite de cal (10 g CaO/litro), até o caldo atingir $\mathrm{pH} 7,5$. Após o aquecimento até ebulição o caldo caleado foi transferido para as provetas do decantador. Foram anotados os volumes de lodo decantado em cada proveta, após 1 hora, sendo expressos em $\mathrm{mL} /$ $100 \mathrm{~mL}$.

A cor ou índice de absorbância no caldo clarificado foi determinada em espectrofotômetro, corrigindo-se o pH a 7,0, a um comprimento de onda de $560 \mathrm{~nm}$, após uma filtração com terra diatomácea, e calculada conforme Meade \& Chen (1977) :

$a_{s}=A_{s} / b c=-\log T_{s} / b c$

onde: $A_{s}=-\log T_{s}=$ absorbância; $T_{s}=$ transmitância; $b=$ espessura da camada líquida, em $\mathrm{cm}$ e

$\mathrm{c}=$ concentração dos sólidos solúveis, em $\mathrm{g} \mathrm{mL}^{-1}$.

\section{Análise Estatística}

O delineamento experimental utilizado foi condicionado a uma dependência frente aos tratamentos, ou seja, estes se referem à adição de fibra em três níveis fixos, caracterizando uma correspondência funcional entre os valores dos tratamentos (variáveis fixas) e as variáveis independentes analisadas. Assim, foi aplicada a regressão na análise da variância, conforme recomenda Gomes (1990). Foi realizada a análise da variância (teste $F$ ) e comparação de médias (teste Tukey), ao nível de $1 \%$ de significância.

A análise de regressão contemplou a regressão linear e quadrática, sendo avaliadas através da sua significância a $1 \%$ e através do coeficiente de regressão linear $(r)$. $O$ desdobramento da regressão foi realizado sempre que a análise de variância foi significativa para tratamentos dentro de cada impureza (teste F).

\section{RESULTADOS E DISCUSSÃO}

Devido a resultados contraditórios na literatura no que diz respeito à presença de impurezas da cana $\mathrm{e}$ seu efeito no caldo, Arceneaux \& Davison (1973) chamaram a atenção para que o problema da generalização do efeito de impurezas secas e verdes pode ser resolvido, adotando-se quantidades de impurezas em base seca. Tem-se assim uma base de equivalência entre as diferentes impurezas num mesmo experimento, ou entre mesmo tipo de impurezas utilizadas em diferentes ensaios na literatura. A metodologia adotada no presente trabalho considera a equivalência entre as diferentes impurezas, tal como mostrado na equação 1. A TABELA 2 mostra, por exemplo, que para se obter um acréscimo de $0,25 \%$ no teor de fibra da amostra de cana, deve ser adicionada uma quantidade de $4,17 \mathrm{~g}$ de folha verde, ou $0,48 \mathrm{~g}$ de folha seca ou $0,28 \mathrm{~g}$ de fibra do colmo. 
TABELA 1 - Composição do extrato aquoso de folhas e bainhas verdes.

\begin{tabular}{lcc}
\hline Componente & Folha Verde & Bainha \\
\hline & $-1,70$ & 96,22 \\
Água & 1,60 & 1,30 \\
Cinzas & 0,19 & 0,32 \\
Lipídios & 0,88 & 0,27 \\
Proteínas & 0,00 & 0,00 \\
Fibra & 3,63 & 1,89 \\
Carboidratos & & \\
\hline
\end{tabular}

TABELA 2 - Quantidade de impureza (folha verde, folha seca ou fibra do colmo) na amostra final preparada, adicionada à amostra de colmo desintegrado, para elaborar os tratamentos.

\begin{tabular}{cccc}
\hline & $\begin{array}{c}\text { Folha } \\
\text { Verde (FV) }\end{array}$ & $\begin{array}{c}\text { Folha } \\
\text { Seca (FS) }\end{array}$ & $\begin{array}{c}\text { Fibra do } \\
\text { Colmo (FC) }\end{array}$ \\
\hline & ---17 & 0,48 & 0,28 \\
$0,25 \%$ & 4,17 & 0,96 & 0,56 \\
$0,50 \%$ & 8,34 & 1,44 & 0,84 \\
\hline $0,75 \%$ & 12,51 & - \\
\hline
\end{tabular}

\section{Cor do Caldo Clarificado}

As médias para cor do caldo e os resultados estatísticos são apresentados na TABELA 3. A Figura 1 mostra os resultados estatisticamente significativos de cor do caldo clarificado influenciados pela adição de folha verde e seca.

A cor do caldo clarificado teve valores aumentados em função da adição de folha verde. A variação da cor do caldo clarificado em relação à testemunha nos vários ensaios individuais, foi de $-0,80$ $a+1,65$ (FV 0,25\%), - 0,95 a + 2,39 (FV 0,50\%) e - 0,83 $\mathrm{a}+2,41$ (FV 0,75\%), com variações médias de $+0,43+$ 1,07 e $+1,24$, respectivamente.

O aumento da cor do caldo clarificado com a adição de folha verde seguiu uma equação de $1^{\circ}$ grau y $=14,262+1,741 x(x=$ acréscimo \% fibra com adição de folha verde) com coeficiente de regressão $r=+0,979$, obtida com as médias gerais que apresentaram regressão linear estatisticamente significativa a $1 \%$ de probabilidade. Segundo essa equação, em média, cada $0,1 \%$ de fibra de FV adicionada à cana aumenta a cor do caldo em 0,174 unidades; e para cada $1 \%$ de FV na cana o aumento é de 0,104 (Figura 1).

Os resultados obtidos concordam com os de outros autores, que também relataram o efeito qualitativo negativo das folhas verdes sobre a cor do caldo clarificado (Balch \& Broeg, 1948; Ivin \& Doyle, 1989). Os resultados do efeito de folha verde sobre variáveis de qualidade tecnológica do caldo (Bovi \& Serra, 1999), mostram a redução do Brix, Pol e Pureza do caldo, proporcionalmente ao aumento da presença de folha verde; da mesma forma também ocorreu a elevação dos açúcares redutores e cinzas, no caldo. Desta forma fica evidente a extração de componentes não-sacarose da folha verde, sendo que o extrato foliar extraído dilui o caldo de cana, reduzindo o teor de sólidos solúveis e sacarose. Por outro lado, o extrato mostra conter substâncias redutoras e cinzas, ao elevar o teor desses componentes no caldo.

A adição de folha seca mostrou resultados similares aos de folha verde, porem com menor impacto considerando os mesmos acréscimos de fibra, mas maiores quando se considera as mesmas quantidades de folha. A variação da cor do caldo clarificado em relação à testemunha, nos vários ensaios individuais, foi de $-0,50 a+0,76$ (FS 0,25\%), $-1,15 a+1,07$ (FS 0,50\%) e - 0,55 a + 2,07 (FS 0,75\%), com variações médias de $+0,02-0,06$ e +0,46, respectivamente.

$\mathrm{O}$ aumento da cor do caldo clarificado com a adição de folha seca seguiu uma equação linear $y=$ $14,142+0,516 x$ ( $x=$ acréscimo \% fibra com adição de folha seca), com coeficiente de regressão $r=+0,487$, obtida com as médias gerais e regressão linear estatisticamente significativa a $1 \%$ de probabilidade. Segundo essa equação, em média, cada $0,1 \%$ de fibra de FS adicionada à cana aumentou a cor em 0,079 unidades; e para cada $1 \%$ de FS na cana o aumento é de 0,269 .

A adição de folha seca mostrou não alterar a qualidade do caldo com relação ao Brix, Pol, Pureza, açúcares redutores e cinzas (Bovi \& Serra, 1999). Todavia, componentes solúveis envolvidos com a formação de cor foram ainda extraídos, mostrando sua presença na folha seca; sua menor influência sobre a cor do caldo clarificado mostra uma menor extração desses compostos em relação à folha verde, ou redução de sua atividade em proporcionar cor, ou ainda a combinação de ambos fatores.

A cor do caldo clarificado não foi alterada com a adição de fibra do colmo. A fibra adicionada nesta forma é um material do qual foram extraídos anteriormente os compostos solúveis, e sua adição representou o papel de um tratamento controle. Este resultado indica que a presença de maior quantidade de fibra pura não é responsável pelas alterações verificadas no caldo clarificado.

\section{Volume de Lodo Decantado}

As médias para volume \% de lodo decantado e os resultados estatísticos são apresentados na TABELA 4. A Figura 2 mostra os resultados estatisticamente significativos de volume de lodo aumentados pela adição de folha verde e seca.

Balch \& Broeg (1948) e Ivin \& Doyle (1989), estudaram o efeito de impurezas de folhas de cana na clarificação do caldo, e não relatam outro efeito negativo a não ser o de elevar a cor do caldo. Outros artigos tratam de mistura de impurezas (folhas, palmito e 
TABELA 3 - Cor do caldo clarificado, de amostras de cana-de-açúcar com teor de fibra acrescido em 0,25, 0,50 e 0,75\% com a adição de folha verde (FV), folha seca (FS) ou fibra do colmo (FC). Comparação entre médias de cada ensaio pelo teste de Tukey (1\%) e coeficientes de regressão significativos (teste $\mathrm{F}$ ).

\begin{tabular}{|c|c|c|c|c|c|c|c|c|c|c|}
\hline \multirow{2}{*}{\multicolumn{2}{|c|}{ TRATAMENTO }} & \multicolumn{8}{|c|}{ ENSAIOS } & \multirow[t]{2}{*}{$\begin{array}{l}\text { MÉD IA } \\
\text { GERAL }\end{array}$} \\
\hline & & 1 & 2 & u & & 5 & 6 & 7 & 8 & \\
\hline & 0,00 & $12,50 \mathrm{c}$ & $13,84 \mathrm{~b}$ & $14,82 \mathrm{~b}$ & $14,68 \mathrm{c}$ & $14,77 \mathrm{a}$ & $14,27 \mathrm{~b}$ & $14,40 \mathrm{a}$ & $14,61 \mathrm{~b}$ & $14,23 \mathrm{c}$ \\
\hline & 0,25 & $14,15 \mathrm{~b}$ & $13,92 b$ & $15,61 \mathrm{a}$ & $15,41 \mathrm{bc}$ & $13,97 \mathrm{~b}$ & $14,87 \mathrm{~b}$ & $14,73 \mathrm{a}$ & $14,61 \mathrm{~b}$ & $14,66 \mathrm{~b}$ \\
\hline \multirow[t]{2}{*}{ FV } & 0,50 & $14,89 a b$ & $15,15 a$ & $15,67 \mathrm{a}$ & $15,78 b$ & $13,82 b$ & 15,87 a & $15,60 \mathrm{~b}$ & $15,61 \mathrm{a}$ & $15,30 \mathrm{a}$ \\
\hline & 0,75 & $14,91 \mathrm{a}$ & $14,83 \mathrm{a}$ & $15,89 a$ & $16,77 \mathrm{a}$ & $13,94 \mathrm{~b}$ & $15,83 \mathrm{a}$ & $15,83 \mathrm{~b}$ & $15,78 \mathrm{a}$ & $15,47 \mathrm{a}$ \\
\hline \multicolumn{2}{|c|}{ Coef. de variação (\%) } & 1,72 & 4,56 & 0,94 & 0,39 & 1,93 & 1,47 & 0,27 & 0,23 & 0,75 \\
\hline \multicolumn{2}{|c|}{ regressão linear (r) } & $+0,909^{* *}$ & ns & $+0,905^{* *}$ & $+0,986^{\star *}$ & ns & $+0,942^{* *}$ & ns & $+0,922^{* *}$ & $+0,979^{* \star}$ \\
\hline \multicolumn{2}{|c|}{0,00} & $12,50 \mathrm{c}$ & $13,84 \mathrm{~b}$ & $14,82 \mathrm{~b}$ & $14,68 \mathrm{a}$ & $14,77 \mathrm{ab}$ & $14,27 \mathrm{~b}$ & $14,40 \mathrm{a}$ & $14,61 \mathrm{ab}$ & $14,23 b$ \\
\hline & 0,25 & $13,26 b$ & $13,57 \mathrm{~b}$ & $14,32 \mathrm{c}$ & $14,90 \mathrm{a}$ & $14,51 \mathrm{~b}$ & $14,67 \mathrm{a}$ & $14,37 \mathrm{ab}$ & $14,41 \mathrm{~b}$ & $14,25 \mathrm{~b}$ \\
\hline \multirow[t]{2}{*}{ FS } & 0,50 & $13,57 b$ & $13,90 \mathrm{~b}$ & $14,89 \mathrm{~b}$ & $14,80 \mathrm{a}$ & $14,68 \mathrm{ab}$ & $13,12 d$ & $13,93 \mathrm{c}$ & $14,50 a b$ & $14,17 \mathrm{c}$ \\
\hline & 0,75 & $14,57 \mathrm{a}$ & $14,84 \mathrm{a}$ & $15,83 a$ & $14,84 \mathrm{a}$ & $14,92 \mathrm{a}$ & $13,72 \mathrm{c}$ & $14,02 \mathrm{bc}$ & $14,79 \mathrm{a}$ & $14,69 a$ \\
\hline \multicolumn{2}{|c|}{ Coef. de variação (\%) } & 0,81 & 0,85 & 0,72 & 0,24 & 1,07 & 2,08 & 0,77 & 0,22 & 0,12 \\
\hline \multicolumn{2}{|c|}{ regressão linear (r) } & $+0,918^{* \star}$ & $+0,775^{\star \star}$ & $+0,737^{\star \star}$ & $+0,539^{* \star}$ & ns & ns & $\mathrm{ns}$ & $+0,491^{\star *}$ & $+0,487^{\star \star}$ \\
\hline \multicolumn{2}{|c|}{0,00} & $12,50 \mathrm{a}$ & $13,84 \mathrm{a}$ & $14,82 \mathrm{a}$ & $14,68 \mathrm{a}$ & $14,77 \mathrm{a}$ & $14,27 \mathrm{a}$ & $14,40 \mathrm{a}$ & $14,61 \mathrm{~b}$ & $14,23 \mathrm{a}$ \\
\hline \multirow{3}{*}{ FC } & 0,25 & $12,60 \mathrm{a}$ & $13,92 \mathrm{a}$ & $14,82 \mathrm{a}$ & $14,70 \mathrm{a}$ & $14,81 \mathrm{a}$ & $14,03 \mathrm{ab}$ & $14,10 \mathrm{~b}$ & $14,81 a b$ & $14,24 \mathrm{a}$ \\
\hline & 0,50 & $12,60 \mathrm{a}$ & $13,97 \mathrm{a}$ & $14,80 \mathrm{a}$ & $14,70 \mathrm{a}$ & $14,90 \mathrm{a}$ & $14,00 a b$ & $13,97 b$ & $14,90 \mathrm{a}$ & $14,24 \mathrm{a}$ \\
\hline & 0,75 & $12,60 \mathrm{a}$ & $13,97 \mathrm{a}$ & $14,80 \mathrm{a}$ & $14,72 \mathrm{a}$ & $14,80 \mathrm{a}$ & $13,97 \mathrm{~b}$ & $13,98 \mathrm{~b}$ & $14,80 a b$ & $14,21 \mathrm{a}$ \\
\hline \multicolumn{2}{|c|}{ Coef. de variação (\%) } & 0,87 & 0,54 & 0,16 & 0,10 & 0,93 & 1,51 & 0,65 & 0,23 & 0,11 \\
\hline
\end{tabular}

Teste $\mathrm{F}:{ }^{\star *}=$ significância ao nível de $1 \%$; ns = não significativo;

ponteiro da cana) e assim seu efeito na clarificação não pode ser isolado em função de determinada impureza, para comparação. O aumento no volume de lodo decantado é indicativo de maiores perdas em açúcar e maior volume de caldo claro que será recirculado após a filtragem do lodo nos filtros rotativos a vácuo.

A presença de folha verde causou aumento no volume do lodo decantado. Seu aumento em relação à testemunha, nos vários ensaios individuais, variou de + $0,13 a+2,80$ (FV 0,25\%), de + 0,8 a + 7,06 (FV 0,50\%) e de $+1,87 \mathrm{a}+6,53$ (FV 0,75\%), com aumentos médios de $+1,08,+2,9$ e $+3,55$, respectivamente.

$\mathrm{O}$ aumento do volume de lodo decantado com a adição de folha verde seguiu uma equação de $1^{\circ}$ grau y $=8,180+4,990 x(x=$ acréscimo \% fibra com adição de folha verde ) com coeficiente de regressão $r=+0,986$, obtida com as médias gerais que apresentaram regressão linear estatisticamente significativa a $1 \%$ de probabilidade. Segundo essa equação, em média, cada $0,1 \%$ de fibra de FV adicionada à cana aumenta 0 volume de lodo em 0,500 \%; e para cada $1 \%$ de FV na cana o aumento é de 0,300. Esses resultados mostram que os componentes extraídos da folha verde também afetam a sedimentação das partículas de impurezas, uma vez que seria pouco provável que sua quantidade fosse suficiente para causar aumento do volume de lodo. As observações de Balch \& Broeg (1948) sobre a clarificação de extrato obtido de folhas verdes são que embora o extrato seja facilmente clarificado com cal e calor, a remoção de cor não é boa. Com relação ao comportamento das partículas relatam que no extrato de folhas verdes os flocos decantam rapidamente e com volume de lodo menor que o de igual volume de caldo, sem mencionar, todavia, a proporção de sólidos naqueles materiais; Para o extrato de folhas secas registram que a cal parece aumentar a dispersão das partículas.

A presença de folha seca também aumenta 0 volume de lodo decantado, tal como para o aumento na cor do caldo clarificado. O aumento do volume de lodo decantado em relação à testemunha nos vários ensaios individuais, variou de - 0,93 a + 1,60 (FS 0,25\%), de $2,00 \mathrm{a}+2,26$ (FS 0,50\%) e de - 1,07 a + 2,80 (0,75\% FS), com variações médias de $+0,19,+0,33$ e $+1,10$, respectivamente.

O aumento do volume de lodo decantado com a adição de folha seca seguiu uma equação de $1^{\circ}$ grau y $=8,059+1,376 x(x=$ acréscimo \% fibra com adição de folha seca ) com coeficiente de regressão $r=+0,921$, obtida com as médias gerais que apresentaram regressão linear estatisticamente significativa a 1\% de probabilidade. Segundo essa equação, em média, cada $0,1 \%$ de fibra de $\mathrm{FS}$ adicionada à cana aumenta 0 volume do lodo decantado em $0,138 \%$; e para cada $1 \%$ de FS na cana o aumento é de 0,717.

A adição de fibra do colmo não causou alteração no volume de lodo decantado, tal como 


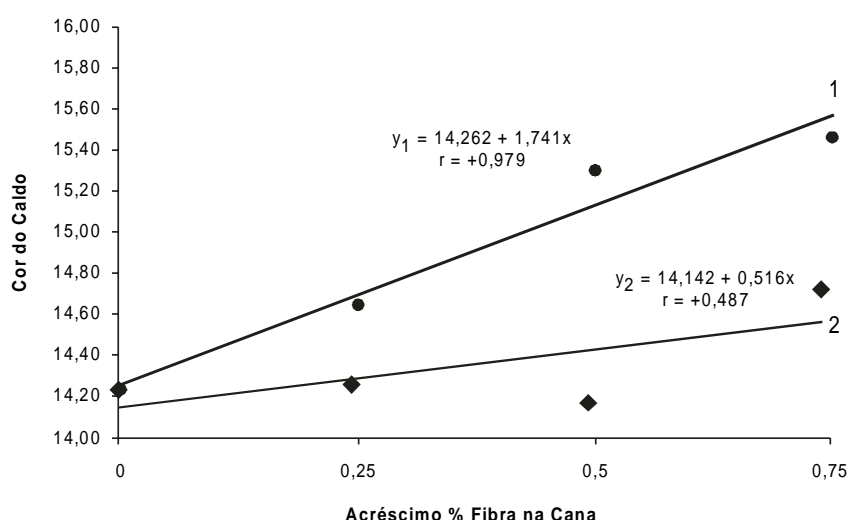

Figura 1 - Cor do caldo em função do acréscimo \% fibra na cana com adição de folha verde (1) e folha seca (2).

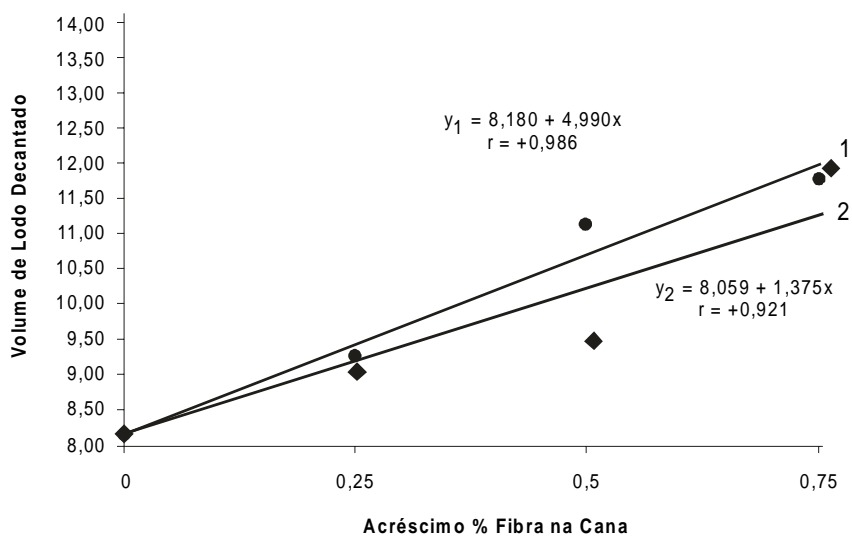

Figura 2 - Volume \% de lodo decantado em função do acréscimo \% fibra na cana com adição de folha verde (1) e folha seca (2). ocorreu para a cor do caldo clarificado, indicando que a maior quantidade de fibra na cana não interfere na extração de componentes sedimentáveis da cana, e tampouco na sedimentação das partículas de impurezas do caldo.

Diversos trabalhos sobre a colheita de cana no Brasil avaliaram a quantidade de folhas presentes nos carregamentos. Em colheita mecânica de cana queimada são relatados valores de 0,4 a $2,2 \%$ para folhas verdes e secas (Furlani et al., 1980). A colheita mecânica de cana crua em toletes apresentou teor de folhas de 1,6 a 4,1\%, de acordo com Tambosco et al. (1977); esses mesmos autores quantificaram as folhas como representando de 1,8 a 2,4\% em cana crua e 1,1 a $1,4 \%$ em cana queimada, para colheita manual com carregamento mecânico. Ripoli \& Mialhe (apud Stupiello \& Fernandes, 1984) avaliaram que as folhas representam $1,5 \%$ em relação à carga de cana, em média. A partir desses dados, se for considerado apenas para avaliação do efeito de impacto das folhas, um teor de 1,5\% para folha verde e igual valor para folha seca, verifica-se que nestas circunstâncias é bastante limitado o efeito prático de folhas verdes e secas sobre a cor do caldo clarificado; o volume de lodo pode ser aumentado mais sensivelmente pela presença de folhas, especialmente das folhas secas. A metodologia de preparo e extração do caldo pela prensa mostraram excelente resposta na extração de componentes das folhas e com conseqüente influência na qualidade do caldo (Bovi \& Serra, 1999).

TABELA 4 - Volume \% de lodo decantado, de amostras de cana-de-açúcar com teor de fibra acrescido em 0,25, 0,50 e $0,75 \%$ com a adição de folha verde (FV), folha seca (FS) ou fibra do colmo (FC). Comparação entre médias de cada ensaio pelo teste de Tukey (1\%) e coeficientes de regressão significativos (teste F).

\begin{tabular}{|c|c|c|c|c|c|c|c|c|c|c|}
\hline \multirow{2}{*}{ TRATAMENTO } & & \multicolumn{8}{|c|}{ ENSAIOS } & \multirow{2}{*}{$\begin{array}{l}\text { MÉDIA } \\
\text { GERAL }\end{array}$} \\
\hline & & 1 & 2 & 3 & 4 & 5 & 6 & 7 & 8 & \\
\hline & 0,00 & $8,67 \mathrm{~b}$ & $9,20 \mathrm{c}$ & $7,47 \mathrm{c}$ & $8,00 \mathrm{~d}$ & $8,00 \mathrm{~b}$ & $8,00 \mathrm{c}$ & $8,00 \mathrm{c}$ & $8,00 \mathrm{c}$ & 8,17 \\
\hline & 0,25 & $8,80 \mathrm{~b}$ & $10,80 \mathrm{~b}$ & $10,27 \mathrm{~b}$ & $9,33 \mathrm{c}$ & $10,13 \mathrm{a}$ & $8,13 \mathrm{c}$ & $8,13 \mathrm{c}$ & $8,40 \mathrm{bc}$ & 9,25 \\
\hline \multirow[t]{2}{*}{ FV } & 0,50 & $15,73 a$ & $12,00 \mathrm{a}$ & $13,20 \mathrm{a}$ & $10,40 \mathrm{~b}$ & $10,40 \mathrm{a}$ & $8,80 \mathrm{~b}$ & $9,07 \mathrm{~b}$ & $8,93 \mathrm{~b}$ & 11,07 \\
\hline & 0,75 & $15,20 \mathrm{a}$ & $12,40 \mathrm{a}$ & $13,60 \mathrm{a}$ & $11,89 a$ & $10,67 \mathrm{a}$ & $10,00 \mathrm{a}$ & $10,13 a$ & $9,87 \mathrm{a}$ & 11,72 \\
\hline \multicolumn{2}{|c|}{ Coef. de variação (\%) } & 1,50 & 2,47 & 2,22 & 2,80 & 6,05 & 3,83 & 2,80 & 3,26 & 0,97 \\
\hline \multicolumn{2}{|c|}{ regressão linear (r) } & $+0,880^{* *}$ & $+0,970$ ** & $+0,963^{\star \star}$ & $+0,998^{\star *}$ & $+0,876^{\star \star}$ & $+0,897^{\star \star}$ & $+0,705^{\star \star}$ & $+0,715^{\star \star}$ & $+0,986^{* *}$ \\
\hline & 0,00 & $8,67 \mathrm{~b}$ & $9,20 \mathrm{c}$ & $7,47 \mathrm{c}$ & $8,00 \mathrm{~d}$ & $8,00 \mathrm{~b}$ & $8,00 \mathrm{c}$ & $8,00 \mathrm{c}$ & $8,00 \mathrm{c}$ & 8,17 \\
\hline & 0,25 & $10,27 \mathrm{~b}$ & $9,60 \mathrm{a}$ & $7,87 \mathrm{a}$ & $8,93 \mathrm{a}$ & $7,40 \mathrm{c}$ & $7,33 \mathrm{c}$ & $7,07 \mathrm{c}$ & $8,40 \mathrm{c}$ & 8,36 \\
\hline \multirow[t]{2}{*}{ FS } & 0,50 & $10,93 \mathrm{a}$ & $7,20 \mathrm{c}$ & $7,47 \mathrm{a}$ & $8,40 a b$ & $8,80 \mathrm{a}$ & $8,13 \mathrm{~b}$ & $7,87 \mathrm{~b}$ & $9,20 \mathrm{~b}$ & 8,50 \\
\hline & 0,75 & $11,47 \mathrm{a}$ & $8,27 d$ & $7,33 \mathrm{a}$ & $8,53 a b$ & $9,33 a$ & $9,60 \mathrm{a}$ & $9,60 \mathrm{a}$ & $10,00 \mathrm{a}$ & 9,27 \\
\hline \multicolumn{2}{|c|}{ Coef. de variação (\%) } & 3,12 & 1,71 & 2,67 & 3,96 & 5,46 & 2,50 & 2,39 & 2,38 & 0,75 \\
\hline \multicolumn{2}{|c|}{ regressão linear $(r)$} & $+0,964^{\star \star}$ & ns & ns & ns & $+0,816^{\star \star}$ & $+0,757^{\star *}$ & $+0,681^{* *}$ & $+0,654^{\star \star}$ & $+0,921^{\text {** }}$ \\
\hline & 0,00 & $8,67 \mathrm{~b}$ & $9,20 \mathrm{c}$ & $7,47 \mathrm{c}$ & $8,00 \mathrm{~d}$ & $8,00 \mathrm{~b}$ & $8,00 \mathrm{c}$ & $8,00 \mathrm{c}$ & $8,00 \mathrm{c}$ & 8,17 \\
\hline & 0,25 & $8,00 \mathrm{a}$ & $9,20 \mathrm{a}$ & $6,80 \mathrm{~b}$ & $8,40 \mathrm{a}$ & $10,13 \mathrm{a}$ & $8,00 \mathrm{a}$ & $8,00 \mathrm{a}$ & $8,00 \mathrm{a}$ & 8,32 \\
\hline \multirow[t]{2}{*}{$\mathrm{FC}$} & 0,50 & $8,01 \mathrm{~b}$ & $9,07 \mathrm{a}$ & $7,20 \mathrm{a}$ & $8,40 a$ & $8,90 \mathrm{~b}$ & $8,13 \mathrm{a}$ & $8,00 a$ & $8,12 \mathrm{a}$ & 8,23 \\
\hline & 0,75 & $8,13 b$ & $9,20 \mathrm{a}$ & $7,20 \mathrm{a}$ & $8,00 \mathrm{~b}$ & $8,00 \mathrm{c}$ & 7,99 a & $7,96 \mathrm{a}$ & $8,00 \mathrm{a}$ & 8,06 \\
\hline \multicolumn{2}{|c|}{ Coef. de variação (\%) } & 1,50 & 2,47 & 2,22 & 2,80 & 6,05 & 3,83 & 2,80 & 3,26 & 0,97 \\
\hline \multicolumn{2}{|c|}{ regressão linear (r) } & $+0,880^{\star \star}$ & $+0,97^{\star \star}$ & $+0,963^{\star \star}$ & $+0,998^{\star \star}$ & $+0,876^{\star *}$ & $+0,897^{\star \star}$ & $+0,705^{\star \star}$ & $+0,715^{\star \star}$ & $+0,986^{\star \star}$ \\
\hline
\end{tabular}

Teste F: ** = significância ao nível de 1\%; ns = não significativo; 


\section{CONCLUSÕES}

Os compostos extraídos das folhas verdes de cana-de-açúcar causam aumento na cor do caldo bem como no volume de lodo decantado. A presença de folha verde aumentou, em média, a cor do caldo e o volume de lodo decantado, em cerca de 0,73 e $3,67 \%$, respectivamente, para cada $1 \%$ de folha verde presente na cana. A folha seca provocou aumento na cor do caldo clarificado de $1,89 \%$, e de $8,78 \%$ no volume do lodo, para cada $1 \%$ de folha seca presente na cana. Considerando as quantidades de folhas verdes e secas em carregamentos de cana, apenas os efeitos sobre 0 volume de lodo podem assumir maior importância prática e especialmente em relação à folha seca, apesar de não ter sido detectada a extração de componentes em extrato preparado com folhas secas.

\section{REFERÊNCIAS BIBLIOGRÁFICAS}

ARCENEAUX, G.; DAVIDSON, L. G. Some effects of trash in cane on milling results. Sugar Journal, v.35, p.33-41, 1973.

BALCH, R.T.; BROEG, C.B. The sugar cane trash problem from a chemical standpoint. Sugar, v.43, p.31-35, 1948.

BOVI, R.; SERRA, G.E. Impurezas fibrosas da cana-de-açúcar e parâmetros tecnológicos do caldo extraído. Scientia Agricola, v.56, p.885-896, 1999.
CLAYTON, J.L. System of cane sugar factory control. 3.ed. Brisbane: ISSCT, 1971. 87p.

GOMES, F.P. Curso de estatística experimental. São Paulo: Livraria Nobel, 1990. 463p.

IVIN, P.C.; DOYLE, C.D. Some measurements of the effect of tops and trash on cane quality. In: AUSTRALIAN SOCIETY OF SUGAR CANE TECHNOLOGISTS, 11., Brisbane, 1989. Proceedings. Brisbane: Watson Ferguson, 1989. p.1-7.

MEADE, G.P.; CHEN, J.C.P. Cane sugar handbook. New York: Wiley, 1977. 947p.

STUPIELLO, J.P.; FERNANDES, A.C. Qualidade da matériaprima proveniente das colhedoras de cana picada e seus efeitos na fabricação de álcool e açúcar. STAB. Açúcar, Álcool e Subprodutos, v.2, p.45-49, 1984.

TAMBOSCO, N.; TEIXEIRA, J.P.B.; GHERALDI FILHO, L.; USTULIN, E.J.; HENRIQUE, J.L. de P.; ALONSO, O.; CORREA, W.J.; FRANCESCHI, L.R.; GERALDI, R.N.; SALATA, J.C.; SERRA, G.E. Trash in mechanical and manual harvesting of sugar cane. In: INTERNATIONAL SUGAR CANE TECHNOLOGISTS, 16., São Paulo, 1977. Proceedings. São Paulo: ISSCT, 1979. v 2, p.1975-1979.

TANIMOTO, T. The press method of cane analysis. Hawaiian Planters Record, v.51, p.133-150, 1964.

ZARPELON, F. Processamento industrial de cana não despontada: experiência da Usina Ester. STAB - Açúcar, Álcool e Subprodutos, v.6, p.37-42, 1988.

$\overline{\text { Recebido em11.02.00 }}$ 